\title{
International Female Perspective on Roller Derby and Body
}

\author{
Image \\ Andrea Eklund $^{1 *} \&$ Barbara Masburg ${ }^{1}$ \\ ${ }^{1}$ Family and Consumer Sciences, Central Washington University, Ellensburg, USA \\ *Andrea Eklund, E-mail: aeklund@cwu.edu
}

\begin{abstract}
The purpose of this study was to investigate the impact participation in roller derby has on body image from an international perspective. An online Qualtrics survey was used to gather data from 814 female skaters from 246 international roller derby leagues. The survey contained quantitative questions from the Multidimensional Body-Self Relations Questionnaire (MBSRQ) along data such as demographic investigation, importance of roller derby, and the reasons for joining and continuing were analyzed using SPSS software. Basic descriptive analysis was completed. Questions seeking qualitative data were coded initially to identify patterns in the data. Further codifying was completed in order to group data into categories and themes. Based upon the data, a typical respondent was Caucasian, 20 to 40 years of age, married/domestic partnership, and has a post-secondary degree. The null hypothesis was rejected as there was a significant difference when comparing means of the MBSRQ prior to joining and currently.
\end{abstract}

\section{Keywords}

body image, roller derby, female, international, MBSRQ

\section{Introduction}

Body image has been defined as a person's subjective picture of one's own physical appearance established both by self-observation and by noting the reactions of others (Barry \& Grilo, 2001; Huange, Norman, Zabinski, Calfas, \& Patrick, 2006, Merriam-Webster.com). Negative body image has been associated with many negative consequences such as a higher likelihood of anxiety, depression, impaired sexual functioning, shame, and low self-esteem (Cash \& Pruzinsky, 2002; Clark \& Tiggermann, 2008; Gillen et al., 2006; Wiederman, 2002) and attempts to control eating behaviours (Lee \& Johnson, 2009; McDonald \& Thompson, 1992). The purpose of this study was to investigate how participation in roller derby affects the body image of participants from an international perspective.

Roller derby began in the 1920s as roller skating races. In 1937 the game evolved into a physical competition between two teams. Roller derby was televised in the late-1940s through the mid-1970s with many boom-and-bust cycles. There were several attempts to revive the sport in the 1980s and 
1990s through theatrical television programs, which were short lived. In 2003 the Texas Rollergirls formed and started the current roller derby movement. Internationally, roller derby is one of the fastest growing women's sports (Women's Flat Track Roller Derby, 2015). In 2006, Roller Derby Worldwide (2014) had 160 leagues registered. Today, 1,515 leagues are registered. The current version of roller derby consists of two teams vying for points played on a flat or banked oval track.

\subsection{Literature Review}

The research in the sport of roller derby is limited and an extensive review of literature revealed no studies specifically examining body image and international roller derby participants. Authors have explored United States roller derby from different perspectives such as roller derby and the media (Adele \& Simone, 2012; Kearney, 2011), femininity (Finley, 2010; Carlson, 2010; Storm, 2008), do it yourself (DIY) ethos (Beaver, 2012), "alternative femininity" (Peluso, 2010), and the relationship with sport and popular music (Pavlidis, 2012). Eklund and Masberg (2013) explored body image in participants in the United States and found participation increased body image among $98 \%$ of the participants. Gieseler (2014) researched participant's performances of sexuality within roller derby and noted that it empowered woman. Local and national media outlets have been documenting the growth of roller derby through participant and league profiles and historical writings (Baqrbee \& Cohen, 2010). Derbyverse is an online video documentation of the experience of belonging to a roller derby league through interviews and publication on the internet (Bradley, 2012).

There are related articles examining other sports and body image although very few are from an international perspective. Zając and Schier (2011) investigated body image dysphoria and motivation to exercise of Canadian and Polish women participating in yoga or aerobics. They reported that "in order for physical exercise to enhance body image it should be based on body mastery, enjoyment, and reasonably moderate activities rather than activities focused on changing appearance or aiming for weight loss". Participants participating in a yoga-type class were found to exercise for health, fitness and most importantly enjoyment reasons. It was found that there was a positive correlation between yoga where the mind-body is the emphasis and increased body image was a result.

Migliaccio and Berg (2007) researched women's participation in tackle football and found that participants had increased physical empowerment, body image, and saw the utility of their bodies and the use of it. Robinson and Ferraro (2004) studied female athletes and non-athletes and found that the athletes had higher body image in comparison to the non-athletes. Downeya et al. (2010) examined body image norms and belly dancing. They found belly dance offers members broad and inclusive body image norms, a lack of pressure for body image conformity, and high levels of body satisfaction among dancers. Overall, the participants indicated that belly dance has a positive influence on body image, and that dancers have generally high body satisfaction even when they perceive some discrepancy between their own body type and social ideals.

Koyuncu et al. (2010) found female athletes feel less social physique anxiety and more body image dissatisfaction. They concluded that lower social physique anxiety and higher body image satisfaction 
in female athletes may stem from the fact that physical activity participation is associated with increased self-esteem and decreased mood disturbance which are related to positive body image. Johns (1996) and Krane et al. (1997) found that participating in sports created pressures that can lead to disordered eating, excessive exercising, and participating with injuries.

There have been many studies devoted to body image in the research literature (Campbell \& Hausenblas, 2009; Rudd \& Lennon, 2000; Kwon \& Shim, 1999; Koyuncu, Tok, Canpolat, \& Catikkas, 2010; Rudd \& Carter, 2006; Krane, Choi, Baird, Aimar, \& Kauer, 2004; Robinson \& Ferraro, 2004), in scholarly books (Weitz, 2010; Damhorst, Miller-Spillman, \& Michelman, 2005; Ussher, 1997; Thompson, 1996; Fallon, Katzman, \& Wooley, 1994), and in the popular press (Grinberg, 2012; Friedman, 2010; Bloom, 2011). Research has found that females are at a higher risk for negative body image than males (Campbell \& Hausenblas, 2009; Elgin \& Pritchard, 2006).

According to Festinger's (1954) theory of social comparison, people have an innate desire to evaluate themselves, and they do this by comparing themselves with others when objective standards are unavailable. Kozar and Damhorst (2009) stated that the social comparison theory emphasizes the individual's use of others for self-reflection, self-evaluation, and self-perception. Social comparative theory has been used in body image research and it was found women tend to socially compare themselves on the basis of appearance (Martin \& Kennedy, 1993; Richins, 1991; Thompson \& Heinberg, 1993). Sociocultural norm theory suggests that one's culture is an extremely powerful determinant of body image, as it is culture that creates standards of beauty by which one judges his/her body (Holmqvist \& Frisén, 2010; Thompson, Heinberg, Altabe, \& Tantleff-Dunn, 1999). Individuals use these standards as a benchmark by which to judge themselves and be satisfied or dissatisfied with themselves (Jung \& Lee, 2006), which is associated with social comparison.

\subsection{Roller Derby Basics}

Flat track roller derby is a high contact sport played on an oval track with members wearing standard gear including quad roller skates. Each team is composed of four Blockers, which make up the pack, a Pivot and one Jammer. Each game or game is comprised of two 30 minutes periods of play and each jam is 2 minutes long. Points are earned when the Jammer passes each opposing player after their initial pass through the pack. Blockers either block opposing jammers or blockers or assist their own Jammer through the pack using four types of blocks. Players can assist their teammates by using an arm, hip or leg whip in which a player transfers her speed to a team mate. Players are given penalties for illegal hits and a player may be ejected from the game if she is sent to the penalty box seven times (Eklund, personal communication May 28, 2012).

The Women's Flat Track Derby Association (WFTDA) is one of the governing bodies. WFTDA has established minimum skill requirements and other standards for the sport including the method of play. Every skater is required to wear protective gear. Leagues are created by interested women who recruit others and create an organization structure with volunteer leaders, managers, and committees. A league may have 10 to 130 members. Each league has bylaws and policies which may include practice and 
game attendance requirements, codes of conduct, new skater policies, skating and game rules, dismissal policies, and insurance requirements.

An important part of belonging to roller derby is the player's roller derby name and number which are chosen after graduating from new skater programs and completing a probation period. Derby names and numbers are registered on an on-line database (http://twoevils.org/rollergirls/). Over 40,500 names and numbers are currently registered. The name and number is approved and monitored and rules are in place so that there are no duplicates, no names ending in verbs, or similarly spelled or pronounced names. Members are then known by their Derby Name. Members also adopt a method of dress which typifies their roller derby personality, a persona. Most leagues have a uniform top. Skaters choose what they wear on the bottom; such as skirts, hot pants, fitted capris, performance leggings, or basketball shorts. Further accessories are added such as leg warmers, fishnet stockings, and customized tights, and knee high socks. Numerous skaters choose to wear make-up and face paint; this can range from wearing slightly more than usual to a full mask of paint and glitter. National level leagues usually have full uniforms. Getting ready for a game is called Derbying Up and a final choice of body adornment is often called a gamefit (Eklund, personal communication May 28, 2012).

\section{Method}

The purpose of this study was to investigate how participation in roller derby affects the body image of the participants.

Research Question 1: Does participation in roller derby affect body image?

Research Question 2: What impact does participation in roller derby have on body image?

Data were collected using an on-line survey instrument in March of 2012. There were 4 sections in the survey: 1) general roller derby participation, 2) Multidimensional Body-Self Relations Questionnaire (MBSRQ; Cash, Winstead, \& Janda, 1986), 3) purchasing, and 4) demographics. The survey was pilot tested using roller derby participants and revisions were made based upon the feedback of the pilot test. Body image was measured using six subscales of the MBSRQ: (a) Appearance Evaluation, (b) Appearance Orientation, (c) Health Evaluation, (d) Health Orientation, (e) Heath Evaluation, and (f) Body Area Satisfaction. The MBSRQ subscales ask individuals to rate themselves from strongly agree (5) to strongly disagree (1) using a series of statements pertaining to how they think, feel, and behave toward their bodies. The Body Area Satisfaction subscale asks respondents to report their satisfaction (5-very satisfied to 1-very dissatisfied) with eight areas of their bodies (i.e., face, hair, lower torso, middle torso, upper torso, muscle tone, weight, height, and overall body appearance). Participants responded to the statements retrospectively prior to joining roller derby and then rated themselves addressing their current perception.

Data analysis was performed using SPSS software with qualitative analysis using the constant comparative method. Demographic, general roller derby participation and spending data were analyzed using descriptive statistics. Descriptive statistics were also calculated for the MSBRQ.

Published by SCHOLINK INC. 
Using an investigator developed questionnaire, data were collected using an on-line survey methodology in March of 2012. The survey instrument contained closed-ended and open-ended questions. Close ended questions were developed to gather demographic data as well as data addressing the motivation for joining and continuing in roller derby. Respondents were also provided space to submit other comments to the motivation questions. Opened ended questions investigated the respondents' views on the differences seen between roller derby and other sports and what specific benefits were gained from membership. The survey instrument was reviewed by 3 members of a roller derby league and then pilot tested using additional roller derby members. Revisions were made based upon the feedback of the review and pilot test. When scant updates were needed, the questionnaire went through a final draft and was published to Qualtrics for data collection.

A mailing list of roller derby leagues was obtained through Roller Derby Worldwide (2012), an on-line compilation of leagues. This list contained links to either a league Facebook page or a league website. Each link was opened and further contact information was sought such as an e-mail address or phone number. Phone number contacts were phoned and e-mails obtained. Each league contact was sent an e-mail asking for his or her assistance in announcing the survey and providing the survey link to their membership through the method most commonly used for league communication. 291 e-mails were sent out to league contacts; leagues were eliminated based upon the type of league (junior or coed, invalid contact information or English not being the primary language. Respondents self-selected and 814 league members responded to the survey. Members of 246 international leagues were represented. Quantitative data such as the demographic investigation, importance of roller derby, and the reasons for joining and continuing were analyzed using SPSS software. Basic descriptive analysis was completed. Questions seeking qualitative data were coded initially to identify patterns in the data. Further codifying was completed in order to group data into categories and themes (Saldana, 2009).

\section{Result}

\subsection{Demographics}

Respondents were predominantly located in three areas; Canada $(38.0 \%, \mathrm{n}=309)$, The United Kingdome and Ireland $(23.5 \%, \mathrm{n}=191)$, Australia, and New Zealand $(22.4 \%, \mathrm{n}=183)$. Further countries of residence included European countries such as Sweden, Germany, Netherlands, Norway, and Finland, 9.9\% $(\mathrm{n}=96)$. There is representation from Japan $(2.3 \%, \mathrm{n}=19)$ and South Africa $(1.8 \%, \mathrm{n}=15)$, a decision was made to include these areas as the participants self-identified as English speaking. The mean age of the respondents was 30.39 years ( $\mathrm{SD}=6.14)$. The 20 to 29 and 30 to 39 year olds accounted for $89.6 \%(n=675)$ of the respondents. White/Caucasian was the dominant race by a large majority, 93.5\% $(\mathrm{n}=752)$. Respondents were asked their sexual orientation, $73.0 \%(\mathrm{n}=590)$ were heterosexual. Nearly half of the respondents were Married or in a Domestic Partnership (44.8\%, $\mathrm{n}=362$ ). A further $27.8 \%(\mathrm{n}=225)$ were Single and $23.6 \%(\mathrm{n}=191)$ were Cohabitating (non married or domestic partnership). A question was asked regarding children; $29.1 \%(\mathrm{n}=235)$ had one or two children living 
with them. Just over $90 \%(90.1 \%, \mathrm{n}=727)$ of the respondents had post secondary education from the associates' degree level through a Ph.D. The most frequent types of professions were Professional/Technical (30.5\%, $\mathrm{n}=274)$, Student $(14.7 \%, \mathrm{n}=118)$, Manager/Official/Proprietor $(9.5 \%$, $\mathrm{n}=77)$, Clerical $(7.8 \%, \mathrm{n}=63)$, and a Household income was predominately less than $\$ 100,000(78.9 \%$ $\mathrm{n}=665)$.

The experience level in roller derby was identified using the length of membership and number of games in which they skated. The respondents were fairly evenly distributed in their length of membership from Fresh Meat ( 1 month to 1 year) $(38.8 \%$; $n=316), 1$ to 2 Years $(34.8 \%$; $n=283)$, to More than 2 years $(26.4 \%$; $n=215)$ of roller derby experience. The number of games showed a wide range but even distribution of experience; No game experience $33.4 \%(\mathrm{n}=271), 1$ to 5 Games, $37.0 \%$ $(\mathrm{n}=301), 6$ or more Games $29.6 \%(\mathrm{n}=240)$. Skating ability jumped from a mean level of $3.12(\mathrm{SD}=2.17)$ prior to joining to $6.6(\mathrm{SD}=1.61)$ currently.

An indication of commitment is shown in the amount spent on roller derby (see Table 1). The majority of respondents $(77.4 \%, \mathrm{n}=620)$ spend between $\$ 26.00$ to $\$ 110.00$. Respondents on average spent more total dollars last year on non-roller derby apparel rather than roller derby apparel. Data from the United States indicates the opposite. More money is spent on roller derby apparel (Eklund \& Masberg, 2013). Respondents identified the most often purchased items and the top three were 1) Socks/Legwear $($ mean $=2.991), 2)$ Wheels (mean= 2.995), and 3) Shorts/Bottoms (mean 3.798).

Table 1. Q34 How Much in Total Did You Spend Last Year on Derby Apparel?

\begin{tabular}{lll}
\hline & Frequency & Percent \\
\hline Less than $\$ 100$ & 40 & 5.0 \\
$\$ 101-\$ 300$ & 135 & 16.7 \\
$\$ 301-\$ 500$ & 231 & 28.6 \\
$\$ 501-\$ 700$ & 196 & 24.3 \\
$\$ 701-\$ 900$ & 78 & 9.7 \\
$\$ 901-\$ 1100$ & 56 & 6.9 \\
More than $\$ 1100$ & 71 & 8.8 \\
& 807 & $100 \%$ \\
\hline
\end{tabular}

\subsection{Body Mass Index (BMI)}

Respondents provided their height and weight which was converted to inches and pounds, and their Body Mass Index (BMI) was calculated using the Center for Disease Control and Prevention (CDC, 2012) body mass index calculation (weight (lb)/[height (in) $]^{2}$ x 703) . Mean BMI was 25.158 ( $S D=6.472)$ which corresponds to a low end Overweight classification (25.00 to 29.9). The respondents were Normal or Ideal Weight $(48.6 \% ; n=378)$, Overweight $(28.1 \% ; n=218)$ or obese $(18.7 \%, n=145)$; 
total overweight and obese was equal to $\mathrm{n}=363$ or $46.8 \%$ of the respondents. The remaining $4.6 \%$ $(\mathrm{n}=36)$ were underweight (see Table 2$)$.

Table 2. Participant Country and BMI

\begin{tabular}{llll}
\hline Country of Residence & & & BMI \\
\hline Canada & $\#$ & $\%$ & $>=25$ \\
United Kingdom & 183 & 22.5 & 56.6 \\
Australia & 139 & 17.1 & 54.9 \\
New Zealand & 44 & 5.4 & 55.4 \\
Sweden & 34 & 4.2 & 39 \\
Japan & 19 & 2.3 & 19.9 \\
Netherlands & 18 & 2.2 & 34.6 \\
Finland & 16 & 2.0 & 43.6 \\
Germany & 16 & 2.0 & 59 \\
South Africa & 15 & 1.8 & 54.9 \\
Norway & 12 & 1.5 & 35 \\
Ireland & 8 & 1.0 & 71 \\
Total & 813 & 100.0 & \\
\hline
\end{tabular}

\subsection{Research Question 1 Does Participation in Roller Derby Affect Body Image?}

Ninety-four percent $(94.3 \%$; $\mathrm{n}=757)$ indicated roller derby had a positive effect on their body image. Further, data were collected addressing body image using the MBSRQ scales: Appearance Evaluation, Appearance Orientation, Health Evaluation, Health Orientation, Health Evaluation (5=Strongly Agree, $1=$ Strongly Disagree), and Body Area Satisfaction (5=Very Satisfied, 1=Very Dissatisfied). Analysis included descriptive statistics and addressing the hypothesis: is there a significant difference between the perception of body image prior to joining roller derby and currently (March 2012). In Table 3, MSRBQ items and scales are presented with their respective mean and standard deviation prior to joining roller derby and currently. In order to address the null hypothesis: there is no significant difference between the scale and mean scores prior to joining roller derby and currently, a paired sample t-test analysis was conducted. The results of the paired sample t-test found that two items, It is/was important that I always look (ed) good, and I check (ed) my appearance in a mirror whenever I could were not significantly different. All other scales were significantly different prior to roller derby and currently at the $\mathrm{P}<.0005$ level except the Appearance Orientation scale where the significance level was $\mathrm{P}<.05$. Based upon the overwhelming number of items which were significantly different the null hypothesis, there is no significant difference between body image prior to joining roller derby and 
currently, was rejected. It is interesting to note the means of the items and scales increased from prior to roller derby and currently except three items on the Appearance Evaluation scale. The mean decreased from prior to currently.

Table 3. MSBRQ Scale and Item Analysis

\begin{tabular}{|c|c|c|c|c|}
\hline \multirow[b]{2}{*}{ Scale and Items } & \multicolumn{2}{|c|}{ Prior to Roller Derby } & \multicolumn{2}{|c|}{ Currently } \\
\hline & M & SD & M & SD \\
\hline Appearance Evaluation (5=Very Satisfied, 1=Very Dissatisfied) & 2.722 & 0.789 & 3.439 & 0.638 \\
\hline My body was/is sexually appealing & 2.849 & 1.034 & 3.493 & 0.929 \\
\hline I like(d) my looks just the way they are/were & 2.693 & 1.006 & 3.347 & 0.929 \\
\hline Most people (would have) consider(ed) me good-looking & 3.117 & 0.879 & 3.401 & 0.797 \\
\hline I like(d) the way I look without my clothes on & 2.367 & 1.130 & 3.274 & 1.047 \\
\hline I like(d) the way my clothes fit me & 2.585 & 1.023 & 3.440 & 0.963 \\
\hline Appearance Orientation ( $5=$ Very Satisfied, $1=$ Very Dissatisfied) & 3.059 & 0.560 & 3.106 & 0.553 \\
\hline Before going out in public, I always notice(d) how I looked & 3.842 & 0.960 & 3.470 & 0.906 \\
\hline *I check(ed) my appearance in a mirror whenever I could & 2.841 & 1.134 & 2.773 & 1.014 \\
\hline I did/do not care what people thought/think about my appearance & 2.543 & 0.980 & 3.221 & 1.053 \\
\hline *It is/was important that I always look(ed) good & 3.006 & 1.009 & 2.953 & 0.950 \\
\hline Fitness Orientation (5=Very Satisfied, 1=Very Dissatisfied) & 2.704 & 0.938 & 3.895 & 0.624 \\
\hline It was/is important that I had/have superior physical strength & 2.455 & 1.083 & 3.729 & 0.933 \\
\hline My physical endurance was/is good & 2.954 & 1.159 & 1.932 & 0.959 \\
\hline I (would have) pass(ed) most physical-fitness tests & 2.800 & 1.246 & 3.815 & 0.927 \\
\hline I did/do things to increase my physical strength/stamina & 2.957 & 1.135 & 4.127 & 0.700 \\
\hline Health Evaluation (5=Very Satisfied, 1=Very Dissatisfied) & 3.010 & 1.083 & 3.799 & 0.776 \\
\hline I was/am a physically healthy person & 3.010 & 1.083 & 3.799 & 0.776 \\
\hline Health Orientation ( $5=$ Very Satisfied, $1=$ Very Dissatisfied) & 2.881 & 0.982 & 3.835 & 0.681 \\
\hline I had/have deliberately develop(ed) healthy life-style & 2.604 & 1.197 & 3.918 & 0.765 \\
\hline I knew/know a lot about physical fitness & 3.015 & 1.172 & 3.780 & 0.810 \\
\hline Body Area Satisfaction (5=Very Satisfied, 1=Very Dissatisfied) & 2.873 & 0.670 & 3.497 & 0.630 \\
\hline Face (facial features, complexion) & 3.360 & 1.000 & 3.643 & 0.840 \\
\hline Hair (color, thickness, texture) & 3.651 & 1.007 & 3.855 & 0.900 \\
\hline Lower torso (buttocks, hips, thighs, legs) & 2.490 & 1.152 & 3.559 & 1.008 \\
\hline Mid torso (waist, stomach) & 2.223 & 1.117 & 3.000 & 1.091 \\
\hline Upper torso (chest or breasts, shoulders, arms) & 2.903 & 1.110 & 3.539 & 0.956 \\
\hline Muscle tone & 2.483 & 0.978 & 3.423 & 0.941 \\
\hline Weight & 2.290 & 1.019 & 3.046 & 1.056 \\
\hline Height & 3.567 & 0.982 & 3.820 & 0.871 \\
\hline Overall appearance & 2.894 & 0.958 & 3.588 & 0.853 \\
\hline
\end{tabular}

$* \mathrm{p}<.001$.

Further analysis using multivariate analysis of variance was conducted to investigate the effects of Country of Residence, BMI, Length of time in roller derby, and Age (dependent variables). Scale 
means prior to joining roller derby and currently were the independent variables. Null Hypothesis; there is no significant effect on the MBSRQ scales of Country of Residence, BMI, Length of time in roller derby or Age. The null hypothesis was rejected for BMI and Age. There was a significant effect for BMI $(F(36,1333)=2.323, \mathrm{P}<.0005$; Wilk's $\lambda=0.835$, partial $\varepsilon 2=.058)$ and Age $(F(48,1739)=1.720$, $\mathrm{P}<.005$; Wilk's $\lambda=0.836$, partial $\varepsilon 2=.044)$. The null hypothesis was not rejected for Length of Membership and Country of Residence. An ANOVA was performed for BMI and Age (independent variables) and the MSBRQ scales (dependent). The results addressing the effects of BMI indicate that nine of the twelve scales were significantly different $(p<.0005)$ (see Table 4$)$. The null hypothesis: BMI does not affect body image was rejected for nine of the twelve scales. For the variable Age, four scales addressing body image prior to joining were significantly different at various levels: prior Appearance Orientation $(\mathrm{F}=3.609, \mathrm{p}<.05)$, Prior Fitness Orientation $(\mathrm{F}=4.254, \mathrm{p}<.005)$, Prior Health Evaluation $(\mathrm{F}=3.172, \mathrm{p}<.05)$, and Prior Health Orientation $(\mathrm{F}=7.445, \mathrm{p}<.0005)$.

Table 4. International Results of the ANOVA Testing for Differences among Age Ranges and BMI Weight Classifications

\begin{tabular}{lll}
\hline \multicolumn{1}{c}{ Scales } & F & \\
& Age & BMI \\
& $\mathrm{df}=4$ & $\mathrm{df}=3$ \\
\hline Prior Appearance Evaluation & 2.053 & $44.634^{*}$ \\
Current Appearance Evaluation & 2.084 & $32.654^{*}$ \\
Prior Appearance Orientation & $3.609^{* * *}$ & 1.406 \\
Current Appearance Orientation & .788 & 2.418 \\
Prior Fitness Orientation & $4.254^{* *}$ & $17.829^{*}$ \\
Current Fitness Orientation & 1.234 & $18.168^{*}$ \\
Prior Health Evaluation & $3.172^{* * *}$ & $27.633^{*}$ \\
Current Health Evaluation & 1.744 & $28.532^{*}$ \\
Prior Heath Orientation & $7.445^{*}$ & $9.152^{*}$ \\
Current Health Orientation & 1.513 & 2.552 \\
Prior Body Satisfaction & .256 & $24.183^{*}$ \\
Current Body Satisfaction & 1.405 & $27.410^{*}$ \\
\hline
\end{tabular}

${ }^{*} \mathrm{p}<.0005 ; * * \mathrm{p}<005 ; * * * \mathrm{p}<.05$.

A correlation was conducted to address the degree and direction of the relationship between the MSRBQ scales and BMI, Length of time in roller derby, and Age. The scale mean was used for this analysis. The BMI negatively correlated with nine scales (see Table 5) at either the $\mathrm{p}<.05$ or $\mathrm{p}<.001$ with the Appearance and Health Evaluation, Fitness and Orientation, and Body Area Satisfaction scales at a 
medium level. As the BMI increased from Underweight, Normal, Overweight, and Obese there was a decrease in the respondents' scores indicating as weight increases there is a subsequent slight decrease in positive body image.

Table 5. International Membership Length, BMI, Age and Country of MSRBQ Scales Using Pearson Correlation

\begin{tabular}{llll}
\hline & Membership Length & BMI & Age \\
\hline Prior Appearance Evaluation & 0.031 & $-0.264^{* *}$ & -0.034 \\
Current Appearance Evaluation & 0.046 & $-.263^{* *}$ & -0.096 \\
Prior Appearance Orientation & -0.016 & 0.053 & -0.105 \\
Current Appearance Orientation & -0.007 & .045 & 0.054 \\
Prior Fitness Orientation & -0.015 & $-0.202^{* *}$ & $.115^{* *}$ \\
Current Fitness Orientation & $.152^{* *}$ & $-0.184^{* *}$ & -0.014 \\
Prior Health Evaluation & -0.49 & $-0.241^{* *}$ & $.101^{* *}$ \\
Current Health Evaluation & $.092^{* *}$ & $-0.211^{* *}$ & 0.049 \\
Prior Heath Orientation & -0.06 & $-0.126^{* *}$ & $.210^{* *}$ \\
Current Health Orientation & $.121^{* *}$ & -0.057 & 0.057 \\
Prior Body Satisfaction & 0.035 & $-0.226^{* *}$ & 0.017 \\
Current Body Satisfaction & 0.006 & $-0.222^{* *}$ & -0.069 \\
\hline
\end{tabular}

Note. Correlation statistics are not reported comparing the MSRBQ scales as the purpose is not to analyze the MSRBQ.

${ }^{*} \mathrm{p}<.05 ; * * \mathrm{p}<.001$.

Length in roller derby and Age had a positive correlation with their current Fitness Orientation, Health Evaluation, and Health Orientation. This correlation indicated as the length of membership in roller derby increases there is a subsequent increase in the respondents' health and fitness. It is interesting to note the items correlating with age would seem to indicate that as one ages there is a decrease of concern on appearance in evaluation or orientation.

Table 6. Characteristics of the Respondents International

\begin{tabular}{|c|c|c|c|c|c|}
\hline Age of the Respondents & \# & $\%$ & $\begin{array}{l}\text { Current Profession or } \\
\text { Employment \# }\end{array}$ & Type of & $\%$ \\
\hline 18 to 19 years & 14 & 1.9 & Professional/technical & 247 & $30.5 \%$ \\
\hline 20 to 29 years & 352 & 46.7 & Manager/official/proprietor & 77 & $9.5 \%$ \\
\hline 30 to 39 years & 323 & 42.9 & Clerical & 63 & $7.8 \%$ \\
\hline 40 to 49 years & 63 & 8.4 & Sales & 25 & $3.1 \%$ \\
\hline
\end{tabular}




\begin{tabular}{|c|c|c|c|c|c|}
\hline 50 to 59 years & 1 & .1 & Crafts/trades & 21 & $2.6 \%$ \\
\hline Total & 753 & 100.0 & Operator & 1 & $0.1 \%$ \\
\hline Race or Ethnicity & $\#$ & $\%$ & Laborer & 13 & $1.6 \%$ \\
\hline White/Caucasian (5) & 752 & 93.5 & Teacher & 60 & $7.4 \%$ \\
\hline Other (6) & 27 & 3.4 & Service worker & 52 & $6.4 \%$ \\
\hline Asian / Pacific Islander / Asian American (1) & 8 & 1.0 & Retired & 1 & $0.1 \%$ \\
\hline Hispanic/Latina/o (3) & 7 & .9 & Homemaker & 35 & $4.3 \%$ \\
\hline Native American (4) & 7 & .9 & Student & 118 & $14.7 \%$ \\
\hline Black / African American (2) & 3 & .4 & Unemployed & 23 & $2.8 \%$ \\
\hline Total & 804 & 100.0 & Other & 6 & $0.7 \%$ \\
\hline Current Relationship status & \# & $\%$ & Artist & 23 & $2.8 \%$ \\
\hline Married / Domestic Partnership (3) & 362 & 44.8 & Scientist/engineer & 0 & $0.0 \%$ \\
\hline Single (1) & 225 & 27.8 & Self Employed/Owner & 25 & $3.1 \%$ \\
\hline $\begin{array}{l}\text { Cohabitating (not married or domestic } \\
\text { partnership) (2) }\end{array}$ & 191 & 23.6 & Heath care & 16 & $2.0 \%$ \\
\hline Separated / Divorced (4) & 29 & 3.6 & Military & 3 & $0.4 \%$ \\
\hline Widowed (5) & 1 & .1 & Total & 809 & $100.0 \%$ \\
\hline Total & 808 & 100.0 & $\begin{array}{l}\text { Approximate Annual } \\
\text { Income \# }\end{array}$ & Household & $\%$ \\
\hline Sexual Orientation & \# & $\%$ & Less than $\$ 25,000$ & 173 & 22.2 \\
\hline Heterosexual & 590 & 73.0 & $\$ 25,000$ to $\$ 49,999$ & 213 & 27.3 \\
\hline Homosexual & 59 & 7.3 & $\$ 50,000$ to $\$ 74,999$ & 153 & 19.6 \\
\hline Bisexual & 130 & 16.1 & $\$ 75,000$ to $\$ 99,999$ & 126 & 9.9 \\
\hline Other & 29 & 3.6 & $\$ 100,000$ to $\$ 124,999$ & 51 & 6.5 \\
\hline Total & 808 & 100.0 & $\$ 125,000$ to $\$ 149,999$ & 29 & 3.7 \\
\hline Highest Education Level & \# & $\%$ & $\$ 150,000$ to $\$ 174,999$ & 8 & 1.0 \\
\hline Some high school & 27 & 3.3 & $\$ 175,000$ to $\$ 199,999$ & 13 & 1.7 \\
\hline Completed high school or GED & 53 & 6.6 & $\$ 200,000$ to 224,999 & 5 & .6 \\
\hline $\begin{array}{l}\text { Junior College/Community College/Trade } \\
\text { School (Associate's Degree) }\end{array}$ & 77 & 9.5 & $\$ 225,000$ to $\$ 249,999$ & 4 & .5 \\
\hline Some college/university & 193 & 23.9 & More than $\$ 250,000$ & 6 & .8 \\
\hline Two year degree & 67 & 8.3 & Total & 781 & 100.0 \\
\hline Four year degree & 237 & 29.4 & & & \\
\hline $\begin{array}{l}\text { A graduate degree (e.g. Masters, Ph.D. or an } \\
\text { M.D.) }\end{array}$ & 153 & 19.0 & & & \\
\hline Total & 807 & 100.0 & & & \\
\hline
\end{tabular}


Table 7. Roller Derby Profile International

\begin{tabular}{lll}
\hline \multicolumn{2}{l}{ Length Participating in Roller Derby } & \\
\hline Mean 17.4 SD 13.77 & $\#$ & $\%$ \\
$1-6$ months & 105 & 12.9 \\
6 months to 1 year & 211 & 25.9 \\
1 to 2 years & 283 & 34.8 \\
2 to 3 years & 136 & 16.7 \\
3 to 4 years & 36 & 4.4 \\
4 to 5 years & 18 & 2.2 \\
More than 5 years & 25 & 3.1 \\
Total & 814 & 100.0 \\
\hline
\end{tabular}

\section{How Many Games Have You Participated in?}

\begin{tabular}{lll}
\hline \multicolumn{3}{l}{ Length Participating in Roller Derby } \\
\hline \multirow{2}{*}{ Zero } & $\#$ & $\%$ \\
1 game & 271 & 33.4 \\
2-5 games & 131 & 16.1 \\
6-10 games & 170 & 20.9 \\
11-15 games & 106 & 13.1 \\
more than 15 games & 76 & 7.1 \\
Total & 812 & 100.0 \\
\hline
\end{tabular}

\subsection{Research Question 2 What Impact Does Participation in Roller Derby Have on Body Image?}

Responses to the open ended questions were analysed using the constant comparative method. A priory themes and clusters identified by Eklund and Masberg (2013) were used to code the data see Table 8 . Additional Themes also emerged including Support motivation, and opinion of others. Negative comments were also coded.

Table 8. Themes and Clusters

\begin{tabular}{ll}
\hline Themes & Clusters \\
\hline The Athletic Body & Muscles, Health \\
Body Acceptance & Of Self, Of Others, General \\
Clothing Choices & Practice/Games, Daily Life \\
Support & Team Support, Mental Motivation, Option of Others \\
\hline
\end{tabular}


Two individuals collaborated on the qualitative analysis in order to address inter-rater reliability. The results of the content analysis of the qualitative comments revealed insight into how participating in roller derby has impacted the body image see Table 9 .

Table 9. Impact on Body Image

\begin{tabular}{lll}
\hline Question 41 Text & $\#$ & $\%$ \\
\hline Muscles & 266 & $24.2 \%$ \\
Body Acceptance Self & 207 & $18.8 \%$ \\
Health & 141 & $12.8 \%$ \\
Body Acceptance Others & 122 & $11.1 \%$ \\
Mental Motivation & 101 & $9.2 \%$ \\
The Athletic Body & 76 & $6.9 \%$ \\
Negative & 53 & $4.8 \%$ \\
Body Acceptance General & 46 & $4.2 \%$ \\
Daily Life & 39 & $3.5 \%$ \\
Support & 21 & $1.9 \%$ \\
Others & 20 & $1.8 \%$ \\
Clothing Choices Practice & 3 & $0.3 \%$ \\
Games & 3 & $0.3 \%$ \\
& 1099 & $100.0 \%$ \\
\hline
\end{tabular}

\subsubsection{The Athletic Body}

Using the body as a tool and for its athletic purposes emerged as a major theme among the participants, "I now see my body as a tool to achieving my derby goals, and therefore I must take care of it much better than I used to". "Yes; not only am I stronger and fitter, but I relish my body as a tool. It seems women are so often valued purely for ornamental reasons, whereas derby gives me something I can use my body for which I am passionate about". Many comments were focused on loving their bodies and improvement in physicality, "Increased confidence. Made me appreciate all the things my body can do, and made me realize I more capable of physical things than initially thought".

Muscles was another cluster that emerged. Participants addressed how their bodies were changing and muscles were developing; "I can see that my body is starting to change shape and become stronger, and I look forward to more of that!" and "Increased my muscle tone. I like feeling my new muscles working in my body, letting me do what I want”. Focusing on being strong and developing their bodies was seen; "I focus more now on being strong and fit than on being skinny as possible, because being skinny and weak would hurt my game, whereas being more muscular and fit would help me".

Respondents discussed focusing on a healthy and active lifestyle and tended to "Stop worrying about 
fatness and start thinking about health, fitness, strength" and "I care about my body, what I am putting into it". Many noted losing weight as a by-product of participation; "I have lost 60 pounds and put on over 25 pounds in muscle in the $21 / 2$ years" and "Lost weight, WAY more healthy now, feel proud of my body". Some even noted that they needed to gain weight to be healthier and stronger for the sport; When you are very underweight, I find it healthy to want to have more muscle or weight in any way. I see how thin I am more clearly after joining derby and seeing my body in photos next to hundreds other body's, and I now understand that to be healthy, I need more weight.

Improved health ailments after joining roller derby were identified with many mentioning reduced asthma, quitting smoking and improvements in depression symptoms.

\subsubsection{Body Acceptance}

Body Acceptance was exemplified by "I see myself in a different way, that I am unique and not to be a cookie cutter female". Through participating in roller derby respondents indicated they accepted parts of their bodies they had previously criticized.

I am a tall woman with a curvy body (large hips, large thighs, and large bust). I liked having curves, but never fully embraced them. Now that I have joined roller derby, I feel like a powerful woman. My thighs are strong and muscular-they are an asset in the sport. My hips are womanly and show that I am healthy. I feel like a warrior woman now. Like an amazon. Every day I look at myself and see a strong woman, who won't take crap from anyone!

Oh hell, I'm going to need a bigger box to explain how derby has changed my body image. Before my body was that thing I had to deal with, like owning a crappy car. It works but you don't want to invest too much in it because generally it's a piece of shit. Now, my body is my muscle car, something I love and I look to improve piece by slow piece. I cultivate it as a place where my power comes from, rather than the thing that holds me back. The funny part? Physically there haven't been huge changes. But now I know what it is capable of, what I am capable of.

Respondents commented that they didn't fit the cultural ideal of "thin" as it is not beneficial to the sport. I am a naturally muscular girl, and therefore also not a small, skinny girl by nature-even if I'm not overweight. Now I truly love my muscular body and actively work to be stronger and fitter because it feels good. I like being a larger girl now, because it gives me an advantage.

Instead of hating my body and the way I look, I know see my curves and know they're good. I look like a real woman, not a stick figure, and I know they're going to be very useful when I start bouting! And being around all these confident women at derby has inspired me to do things I've always wanted to like have blue hair and start getting my half sleeve done that I've been dreaming about for almost 10 years!

Knowing that different body types can be fit and strong and not look like a magazine "All shapes and sizes are welcomed and I feel like there is no judgment" epitomizes a large number of participants. Seeing other players with diverse body shapes and sizes was noted as helping improve body image. Many also discussed everyone having their own place on the track, that there is a role for everyone no 
matter their body and admiring those bodies rather than criticizing them.

I have become more appreciative of the strength and diversity of women's body shapes and am much less likely to despair a petite girl as anorexic or a larger girl as fat-both can be powerful and amazing derby players and I am grateful for their strengths as my teammates on the track. This also means I'm less likely so hard in myself.

I am constantly amongst women who are confident in their bodies, and site for fitness and strength over being thin. There is a greater representation of different weight shapes and sizes in derby than any other sport I have encountered. There are women who weigh $100 \mathrm{~kg}$ what are fast, fit, strong and confident-and there are women who weigh $50 \mathrm{~kg}$ what are fast, fit, strong and confident. This so rare and so empowering.

Our league has so many diverse women of varying shapes and athletic abilities that 1) all pass the same standards, 2) are positioned in roles that reflect their abilities for the mutual goal of success and accomplishment in derby.

It's great to see women of all shapes and sizes getting stuck in, and I feel like their confidence in their appearance rubs off on me, reminds me it's not what matters.

While there were many positive views there were some that were negative, specifically with comparing themselves to others. "You don't feel like you have to live up to the ideal woman the media portrays. But on the other hand, there are a lot of really fit women playing roller derby, who you can compare yourself (unfavorably) with" and "I think women feel they are allowed to be strong, and that there is now a use for their body they might not have otherwise appreciated. But also, you are around a lot of women who are dressed in tighter clothing-there are more women to compare yourself against who exercise at the same level, so you can sometimes feel like you're still not fit/strong/attractive by comparison". There were a handful of comments that mirrored these with dually noting the positive aspects and some of the negative that some participants experience.

\subsubsection{Clothing Choices}

Participation in roller derby affected the respondents' choice in clothing. Participants discussed wearing clothing that was more fitted while practicing, during games, and in their daily attire. A large part of roller derby is dressing up during games, called "derbying up". Most players create an alter-ego which encompasses their name, number and body adornment with the use of makeup, clothing and/or accessories. The form fitted clothing ranges from tights, short skirts, bicycle style shorts under basketball style shorts, to athletic performance clothing.

Participants noted that they were more "comfortable" wearing revealing clothing during practices and games and this was due to the trust they had of their teammates; "I am happy to wear revealing clothes with my team mates because it is comfortable and I trust them", and "I feel like I can wear whatever I want and not get judged". Some were not quite ready to wear revealing clothing in public but did wear revealing clothing at practices; "I wear clothes I never would have before (booty shorts and skirts!), but only in training-still not brave enough to wear new things outside of derby". 
Wearing more revealing clothing in their daily lives due to increased confidence in their bodies was also a common theme; "I would NEVER have left the house in leggings now I wear tights and tiny shorts! And feel good in them!" Wearing clothing that correctly fit and not too baggy was also an impact of improved body image.

I had clothes that I wouldn't wear before derby because I thought they were too tight and made me look fat. The reality is that I just preferred baggier clothes that hid my body. Now, I actually weight a bit more that I did before I started playing derby, but I like my body so much more. I wear clothes that fit me properly and can see that they look good on me.

Due to the increased exercise and in turn more muscle mass there were some issues with how clothing fit their new bodies; "Its hard to find pants that fit my calves and thighs now though! LOL". Participants noted the issue of clothing not fitting, specifically their larger thighs but saw it as a sacrifice for being stronger and a better player.

Unfortunately we don't have trainers in our league so a lot of us have "bulked up" in a bad way. The more muscle I'm putting on the bigger I become, yet I have been unable to lose any fat. So I'm getting bigger and bigger in $\mathrm{cms}$ which now makes it impossible for me to purchase any clothes from the so called "normal" range and have to purchase everything in the plus size range. Oh and my thighs pretty much don't fit in any clothing other than stretch pants anymore...but meh, at least my thighs are strong...just hard playing with very skinny girls who wish to buy uniforms that flatter them, as they tend not to consider us bigger blockers and what flatters our shape and size...

\subsubsection{Support}

Support from teammates was very important to many of the participants; "I've never known a group of women who are so genuinely supportive that's really helped", and "I see the support that the girls offer to less confident women". Positive feedback was also noted as impactful on participants; "I receive more positive reinforcement on my physicality/athleticism; I engage in healthier habits".

General participation also was discussed in assisting with mental motivation and more positive daily feelings; "Exercise helps lift my mood and eases my depressive thoughts, tones my body and has helped me loose weight and improve muscle tone", and "I feel better inside physically and mentally". One participant noted she is larger than when she started but much happier since joining; "I am happier now. That also means I am fatter. Before derby I was depressed and didn't eat. Derby saved my soul. It also introduced me to my husband who is a referee. He thinks my body is beautiful".

Worrying less about what others think of them was discussed and epitomized by one participant who noted "I just don't care what other people think. I am the shape I am and I love it and other people should deal with that". Another skater noted that "Rather than changing how it makes me feel about myself, now I just don't care what other people think of me". This is especially true when on skates; When I am skating in particular, I don't care what other people think. I'm quite happy whizzing around the track in tiny shorts, and equally as happy to get the bus home drenched in sweat still wearing the tiny shorts. It's nice too because I'm building up muscle one I used to have before, which makes me 
feel better about my body.

\section{Discussion}

Participation in roller derby does affect body image and for the majority of respondents, $94.3 \%$ roller derby participation had a positive effect on their body image. Quantitative data using the MSRBQ demonstrated that there is a significant difference between body image prior to joining roller derby and their body image currently (March 2012). One item in the Appearance Orientation scale, It is/was important that I always look (ed) good and the scale mean indicated there was not a significant difference prior to joining roller derby and currently. It is interesting to note, that for all scales and items except 3 out of the 4 items on the Appearance Orientation scale and the scale itself, the respondents more strongly agreed with the statement currently. Appearance Orientation involves an individual's investment in her appearance indicating paying attention to their appearance and time spent on grooming or effort to "look good". It seems that these efforts have not changed.

BMI did affect body image scores. As BMI increased there was less agreement indicating a lower body image. These findings support the recent studies that have found that a higher BMI or actual body size was negatively correlated with body image and appearance constraints (Liechty, Freeman, \& Zabriskie, 2006; Dijkstra \& Barelds, 2011). Meanwhile for Appearance Orientation there was not an effect based upon BMI.

Age had a small negative correlation with Current Appearance Evaluation and Prior Appearance Orientation, and a small positive correlation with Current Health Orientation. Length of membership had a positive effect on Current Fitness Orientation and Current Health Orientation. This research supports Robinson and Ferraro (2004) in that sports participation not only helps maintain physical health in women but also encourages a healthier body image.

Four themes emerged in the qualitative analysis: 1) the athletic body with clusters addressing athleticism or physicality, muscle development, and a healthy lifestyle, 2) body acceptance with clusters addressing their own bodies, their teammates, and general body acceptance, 3) clothing choices during practice, games, and in daily life, and 4) support with clusters in team support, mental motivation and option of others.

\subsection{Theme 1 The Athletic Body}

Looking at the body as a tool and from an athletic perspective was a common theme. They "appreciate their [my] body for what it can do" and are "less judgemental". This was largely due to seeing their bodies as tools and focusing on what they could do with their bodies to be more competitive rather than focusing on what it looked like; "I focus more now on being strong and fit than on being skinny as possible, because being skinny and weak would hurt my game, whereas being more muscular and fit would help me".

These findings are similar to previous studies that revealed that female athletes expressed empowerment, satisfaction, and enjoyment through physically assertive sports (Baird, 2001; 
Hargreaves, 1993; Rail, 1996; Theberge, 1997). The findings are similar to the findings of Sisjord and Sisjord (2009) which found that females on the Norwegian national wrestling team emphasized the physicality of the sport. To be successful the participants discussed having an athletic body and valuing their bodies for how they can perform and admiring others athletic bodies. They also discussed the "toughness" that they need and repeatedly emphasized being strong. Participants acknowledged the cultural ideal of thinness but noted that they do not fit the ideal and do not want to due to needing the strength and muscle to be successful in the sport. This mirrors the research done by Migliaccio and Berg (2007), and Harris (2005) who researched woman's tackle football players. The football players echoed our participant in needing to be strong and muscular to be effective.

\subsection{Theme 2 Body Acceptance}

A major theme for $29.9 \%$ of participants was the acceptance of their bodies and appreciation of others' bodies. Again participants noted not fitting the cultural ideal, the majority of these countries is a thinner silhouette, but didn't need to meet these cultural ideals; "I don't feel the need to conform to body stereotypes because I know my body is strong and healthy". These results are similar to the findings of Migliaccio and Berg (2007) whereby the female football cohorts are more accepting and inviting to a broader range of body types as they are seen as more beneficial to the team. These findings mirror Eklund and Masberg's (2014) research on roller derby participation and body image for participants in the United States.

Participants expressed that "All shapes and sizes are welcomed' and they...feel like there is no judgement". This is similar to Migliaccio and Berg (2007) who found that tackle football "allows for a range of player sizes, from bigger line players to smaller kickers and running backs. The benefit of this diversity was voiced by several players, who considered football to be a game that is uniquely open to women of a variety of sizes and skill sets". Seeing a variety of body types and how confident others were of their various shaped bodies helped them have more confidence in their own body. There were a handful participants that did discuss that they struggled at times with their body image but that overall it had greatly improved from when they started roller derby. Our body cathexis is the degree of satisfaction we have with our bodies (Miller-Spillman, Reilly, \& Hunt-Hurst, 2012). The above participant statement shows what many people experience, at times a person's contentment with their bodies can fluctuate from their baseline satisfaction. It is noted that participation in roller derby assist with improvement of body cathexis and in time will level spikes of dissatisfaction.

\subsection{Theme 3 Clothing Choices}

The majority of the participants had higher self-confidence in their bodies and were "not as self-conscious about wearing more revealing clothing" during the day, at practice and in games; "I am more confident in my body, I enjoy the changes and I wear short shorts now, not just on the track, but in the real world too", and "I am happy now to be seen in public in a swimsuit". Respondents emphasized being comfortable in their bodies and seeing others wear more fitted clothing gave them confidence in wearing similar clothing. This is contradictory to recent research. Krane et al. (2004) 
found athletes who wore revealing uniforms expressed discomfort in their uniforms, concern with how they looked in their uniforms, and worried that they would be perceived as fat or too big. Price and Pettijohn (2004) examined the affect of ballet dance attire on body and self-perceptions of female dancers. Dancers were allowed to wear loose-fitting outfits or "junk" for one class and tight-fitting garments (leotards and tights) for another class. When dancers wore "junk" they reported a significant increase in positive body image and self-perceptions compared to when they wore leotards and tights. They found wearing tight-fitting clothing that accentuates body features was partially responsible for increased body concerns. Our participants indicated the opposite, roller derby allows participants to have more confidence in their bodies and are willing to wear more revealing clothing.

\subsection{Theme 4 Support}

"My teammates are my second family" was often mentioned. They see their fellow teammates as a chosen family. The relationships are dynamic and built on trust. Supporting each other in times of need on and off the track was an important part of transforming the team into a family. Migliaccio and Berg (2007) found similar themes; "we did discover strong patterns related to the positive elements of their participation in professional football-including teamwork, a sense of family, a chance to meet a diverse group of people, and the physicality and joy of playing". When players were asked to describe their teammates they did so in terms of a family, similar to our participants.

Motivation, empowerment and inspirational was noted from many participants. Support from others empowered the players and motivated them to challenge themselves on and off the track. Looking to other skaters for their skills was inspirational to the participants and made them want to push themselves to a higher level in the sport. Migliaccio and Berg (2007) found that tackle football was a source of empowerment for the participants which included the use of their bodies and minds equally. This is concurrent with our participants that pointed out the physical and mental part of the game and developing those with their teammates.

Independence from outsider's thoughts and feelings about their body shape, what they wear and thoughts in general was a strong topic. One participant noted "I just don't care what other people think. I am the shape I am and I love it and other people should deal with that". Focusing on how they feel about themselves was a shift for participants; "I don't think so much on what other people think and concentrate more on how I feel".

\subsection{Negative}

$4.8 \%$ of the participants experienced a lower body image due to involvement in roller derby. Comparing themselves to others was a common theme for these participants; "I compare myself to others all the time and feel overweight”, and “...I am never strong enough, never fast enough which wasn't an issue before roller derby. I constantly compare myself to other people with more athletic bodies, which I never really did before. I certainly value my body less since starting derby”. Festinger's (1954) social comparison theory is very evident as respondents indicated comparing themselves within their roller derby culture. Some indicated a negative effect on their body image and comparing 
themselves to higher level or more experienced players; “...I now compare myself to elite team and league players and realize I am not nearly as fit as them, and do not look like them. 'and'...there are more women to compare yourself against who exercise at the same level, so you can sometimes feel like you're still not fit/strong/attractive by comparison". For these respondents focusing on the body as an athletic tool was a similar theme, although they felt pressure to be equal to a higher level player whether real or perceived.

\subsection{Conclusions, Limitations and Future Research}

There were limitations in the current investigation. Respondents were only surveyed at one point in time and asked to answer questions retrospectively. Although there was a large sample, this convenience sample limits the generalizability of the results. Future studies of participation and the impact on body image within junior roller derby (for ages 6-18) would be beneficial considering young girls are the most influenced by the cultural ideal and media images. In investigating other research tackle football has many similarities to roller derby. It would be interesting to do a comparative study of roller derby and football players in terms of body image, perspectives on femininity in a high contact sport and clothing.

The research questions 1) Does participation in roller derby affect body image, and 2) how does participation in roller derby effect body image have been thoroughly examined. It is clear that participation in roller derby improves body image from this research. In comparing the international data used in this study with Eklund and Masberg's (2014) data from the United States it is clear that no matter the participant's geographic location that participation does increase body image and with similar themes and clusters. Roller derby challenges cultural norms and expectations for women by promoting a variety of body shapes and sizes and looking at the body as a tool in its skill and muscular development. Participants developed a sense of community and family within their team and through that supportive environment found it to be motivational and empowering. Rudd and Lennon (2000) found that participation in women's athletics help to increase feelings of self-esteem which is seen in this research.

\section{References}

Adele, P., \& Simone, F. (2012). Becoming roller derby grrrls: Exploring the gendered play of affect in mediated sport cultures. International Review for the Sociology of Sport, 48(6), 673-688.

Baird, S. (2001). Femininity on the pitch: An ethnographic study of female rugby players (1th ed.). Bowling Green: Bowling Green State University.

Barbee, J., \& Cohen, A. (2010). Down and Derby, the Insiders Guide to Roller Derby. Berkley: Publishers Group West.

Barry, D., \& Grilo, C. (2001). Eating and body image disturbances in adolescent psychiatric inpatients: Gender and ethnicity patterns. International Journal of Eating Disorders, 32, 335-343.

Beaver, T. D. (2012). "By the skaters, for the skaters" The DIY ethos of the roller derby revival. 
Journal of Sport and Social Issues, 36(1), 25-49.

Bloom, A. (2011, November). Dear Every Woman I Know, Including Me. O. The Oprah Magazine, 12(11), 187. Retrieved from http://www.oprah.com/spirit/Improving-Body

$\begin{array}{lllll}\text { Bradley, } & \text { T. } & \text { (2012). } & \text { Derbyverse. } & \text { Retrieved }\end{array}$ http://www.derbylife.com/articles/2012/07/derbyverse_todd_bradley

Body image. (n.d.). Retrieved November 1, 2014, from http://www.merriam-webster.com/medical/body image

Campbell, A., \& Hausenblas, H. (2009). A Review and Critique Affects of Exercise Interventions on Body Image: A Meta-analysis. Journal of Health Psychology, 14, 780.

Carlson, J. (2010). The female significant in all-women's amateur roller derby. Sociology of Sport Journal, 27, 428-440.

Cash, T., \& Pruzinsky, T. (Eds.). (2002). Body image: A handbook of theory, research, and clinical practice. New York: Guilford Press.

Cash, T., Winstead, B., \& Janda, L. (1986). Body image survey report: The great American shape-up. Psychology Today, 20, 30-34.

Center for Disease Control and Prevention. (2012). Retrieved from http:// www.CDC.gov

Chattaraman, V., \& Rudd, N. (2006). Preferences for Aesthetic Attributes in Clothing as a Function of Body Image, Body Cathexis and Body Size. Clothing and Textiles Research Journal, 24, 46.

Clark, L., \& Tiggermann, M. (2008). Sociocultural and individual psychological predictors of body image in young girls: A prospective study. Developmental Psychology, 44, 1124-1134.

Damhorst, M., Miller-Spillman, K., \& Michelman, S. (2005). The meaning of dress (2th ed.). New York: Fairchild Publications.

Dijkstra, P., \& Barelds, D. P. H. (2011). Women's meta-perceptions of attractiveness and their relations to body image. Body Image, 8, 74-77.

Downeya, D., Reelb, J., SooHoob, S., \& Zerbib, S. (2010). Body image in belly dance: Integrating alternative norms into collective identity. Journal of Gender Studies, 19(4), 377-393.

Eklund, A. (2012, May 28). Basics of Roller Derby [Personal interview].

Eklund, A., \& Masberg, B. (2014). Participation in Roller Derby, the Influence on Body Image. Clothing and Textiles Research Journal, 32(1), 49-64.

Elgin, J., \& Pritchard, M. (2006). Gender differences in disordered eating and its correlates. Eat Weight Disord, 11(3), 96-101.

Festinger, L. (1954). A theory of social comparison processes. Human Relations, 7, 117-140.

Finley, N. J. (2010). Skating femininity: Gender maneuvering in women's roller derby. Journal of Contemporary Ethnography, 39(359).

Friedman, S. (2010, November). Doctor: Teen girls misinformed on body image, sex. Retrieved from http://www.usatoday.com/yourlife/your-look/2010-11-05-teen-girls-sex_N.htm

Gieseler, C. (2014). Derby drag: Parodying sexualities in the sport of roller derby. Sexualities, 17(5/6), 
$758-776$.

Gillen, M., Lefkowitz, E., \& Shearer, C. (2006). Does body image play a role in risky sexual behavior and attitudes? Journal of Youth and Adolescence, 35, 243-255.

Grinberg, E. (2012, March 9). Sex, lies and media: New wave of activists challenge notions of beauty. Retrieved from http://articles.cnn.com/2012-03-09/living/living_beauty-media

Hargreaves, J. A. (1993). Sporting females: Critical issues in the history and sociology of women's sports. NewYork: Routledge.

Harris, J. (2005). The Image Problem in Women's Football. Journal of Sport and Social Issues, 29(2), 184-197.

Holmqvist, K., \& Frisén, A. (2010). Body dissatisfaction across cultures: Findings and research problems. European Eating Disorders Review, 18, 133-146.

Huange, J., Norman, G., Zabinski, M., Calfas, K., \& Patrick, K. (2006). Body image and self-esteem among adolescents undergoing an intervention targeting dietary and physical activity behaviors. Journal of Adolescent Health, 40, 245-251.

Johns, D. (1996). Fasting and feasting: Paradoxes of the sport ethic. Sociology of Sport Journal, 15, 41-63.

Jung, J. (2006). Media Influence: Pre- and Postexposure of College Women to Media Images and the Affect of Mood and Body Image. Clothing and Textiles Research Journal, 24, 335.

Jung, J., \& Lee, S. H. (2006). Cross-cultural comparisons of appearance self-schema, body image, self-esteem, and dieting behavior between Korean and U.S. women. Family and Consumer Sciences Research Journal, 34, 350-365.

$\begin{array}{llll}\text { Kaiser Health } \quad \text { Foundation. } & \text { (2012). Retrieved }\end{array}$ http://www.statehealthfacts.org/comparebar.jsp?ind=90\&cat=2

Kearney, M. C. (2011) Tough girls in a rough game. Feminist Media Studies, 11(3), 283-301.

Koyuncu, M., Tok, S., Canpolat, A., \& Catikkas, F. (2010). Body Image Satisfaction and dissatisfaction, Social Physique Anxiety, Self-esteem, and Body Fat Ratio in Female Exercisers and Nonexercisers. Behavior and Personality, 38(4), 561-570.

Kozar, J., \& Damhorst, M. (2009). Comparison of the Ideal and Real Body as Women Age: Relationships to Age Identity, Body Satisfaction and Importance, and Attention to Models in Advertising. Clothing and Textiles Research Journal, 27, 197.

Krane, V., Choi, P., Baird, S., Aimar, C., \& Kauer, K. (2004). Living the Paradox: Female Athletes Negotiate Femininity and Muscularity. Sex Roles, 50(5/6).

Kristin, S., M., \& Sisjord, K. (2009). Elite Women Wrestlers' Muscles: Physical Strength and a Social Burden. International Review for the Sociology of Sport, 44(2-3), 231-246.

Kwon, Y. H., \& Shim, S. (1999). A structural model for weight satisfaction, self-consciousness and women's use of clothing in mood enhancement. Clothing and Textiles Research Journal, 17(4), 203-212. 
Lee, J., \& Johnson, K. (2009). Factors related to engagement in risky appearance management behaviors. Clothing and Textiles Research Journal, 27, 163-178.

Liechty, T., Freeman, P., \& Zabriskie, R. (2006). Body Image and Beliefs Agame Appearance: Constraints on the Leisure of College-Age and Middle-Age Women. Leisure Sciences, 28, 311-330.

Martin, M. C., \& Kennedy, P. F. (1993). Advertising and social comparison: Consequences for female preadolescents and adolescents. Psychology and Marketing, 10, 513-530.

McDonald, K., \& Thompson, J. (1992). Eating disturbance, body image dissatisfaction, and reasons for exercising: Gender differences and correlational findings. International Journal of Eating Disorders, 11, 289-292.

Migliaccio, T., \& Berg, E. (2007). Women's Participation in Tackle Football: An Exploration of Benefits and Constraints. International Review for the Sociology of Sport, 42(3), 271-287.

Miller, S. K., Reilly, A., \& Hunt, H. P. (2012). The Meaning of Dress (3rd ed.). New York: Bloomsbury Publishing.

Muscat, A., \& Long B. (2008). Critical comments agame body shape and weight: Disordered eating of female athletes and sport participants. Journal of Applied Sport Psychology, 20, 1-24.

Pavlidis, A. (2012). From Riot Grrrls to roller derby? Exploring the relations between gender, music and sport. Leisure Studies, 31(2), 165-176.

Peluso, N. M (2010). High heels and fast wheels: Alternative femininities in neo-burlesque and flat track roller derby (Doctoral dissertation). Retrieved from http://digitalcommons.uconn.edu/dissertations/AAI3464369

Perry, C., \& March, H. (2000). Listening to self-talk, hearing self-concept. In M. Andersen (Ed.), Doing Sport Psychology (pp. 61-75). Portland: Human Kinetics

Price, B., \& Pettijohn, T. (2006). The affect of ballet dance attire on body and self-perceptions of female dancers. Social Behavior and Personality, 34(8), 991-998.

Rail, G. (1996). Physical contact in women's basketball: A phenomenological construction and contextualization. International Review for the Sociology of Sport, 31, 439-452.

Richins, M. L. (1991). Social comparison and the idealized images of advertising. Journal of Consumer Research, 1, 718-783.

Robinson, K., \& Ferraro, F. (2004). The relationship between types of female athletic participation and female body type. The Journal of Psychology, 138(2), 115-128.

Roller Derby Worldwide, derby roster. (2014). Retrieved from http://www.derbyroster.com/index.php

Rudd, N., \& Carter, J. (2006). Building positive body image among college athletes: A socially responsible approach. Clothing and Textiles Research Journal, 24, 363.

Rudd, N., \& Lennon, S. (2000). Body image and appearance-management behaviors in college women. Clothing and Textiles Research Journal, 18(3), 152-162.

Rudd, N., \& Lennon, S. (2001). Body image: Linking aesthetics and social psychology of appearance. 
Clothing and Textiles Research Journal, 19(3), 120-133.

Saldana, J. (2010). The coding manual for qualitative researchers. Los Angeles: Sage Publications.

Storms, C. E. (2008). "There's no sorry in roller derby": A feminists examination of identity of women in the full contact sport of roller derby. New York Sociologist, 3, 66-86.

Theberge, N. (1997). It's part of the game: Physicality and the production of gender in women's hockey. Gender and Society, 11, 69-87.

Thompson, J. K., Heinberg, L. J., Altabe, M., \& Tantleff-Dunn, S. (1999). Exacting beauty: Theory, assessment, and treatment of body image disturbance. Washington, DC: American Psychological Association.

Thompson, J., \& Heinberg, L. (1993). Preliminary test of two hypotheses of body image disturbance. International Journal of Eating Disorders, 114, 59-63.

Ussher, J. (1997). Fantasies of Femininity: Reframing the Boundaries of Sex (1th ed.). New Brunswick: Rutgers University Press.

Weitz, R. (2010). The politics of women's bodies (3rd ed.). New York: Oxford University Press.

Wiederman, M. W. (2002). Body image and sexual functioning. In T. F. Cash, \& T. Pruzinsky (Eds.), Body image: A handbook of theory, research, and clinical practice (pp. 287-294). New York: Guilford Press.

Women's Flat Track Roller Derby. (n.d.). Retrieved February 25, 2015, from https://wftda.com/roller-derby

World Health Organization (WHO). (2013). Retrieved from http://apps.who.int/bmi/index.jsp

Zając, A., \& Schier, K. (2011). Body image dysphoria and motivation to exercise: A study of Canadian and Polish women participating in yoga or aerobics. Archives of Psychiatry and Psychotherapy, 4, $67-72$. 